\title{
A look at forensic dentistry Part 1: The role of teeth in the determination of human identity
}

\author{
I. A. Pretty, ' and D. Sweet, ${ }^{2 *}$
}

\section{Forensic dentistry can be defined in many ways. One of the more elegant definitions is simply that forensic dentistry represents the overlap between the dental and the legal professions. This two-part series presents the field of forensic dentistry by outlining two of the major aspects of the profession: human identification and bite marks. This first paper examines the use of the human dentition and surrounding structures to enable the identification of found human remains. Conventional and novel techniques are presented.}

s we enter a new millennium, society is Afaced with fresh challenges in every conceivable area. Despite leaps in modern technology, medical breakthroughs and the geographical changes that the last century has brought, crime still persists in all aspects of our lives. Violent and heinous activities that shatter the lives of victims, their friends and families occur everyday. Often, little can be done to repair such damage. The apprehension and subsequent prosecution of the perpetrator(s) is essential to maintain law and order. Through the specialty of forensic odontology, dentistry plays a small but significant role in this process. By identifying the victims of crime and disaster through dental records, dentists assist those involved in crime investigation. Always part of a bigger team, such personnel are dedicated to the common principles of all those involved in forensic casework: the rights of the dead and those who survive them.

The most common role of the forensic dentist is the identification of deceased individuals. ${ }^{1}$ Dental identification takes two main forms. Firstly, the most frequently performed examination is a comparative identification that is used to establish (to a

${ }^{1}$ Graduate Student, University of Liverpool, UK

${ }^{2 *}$ Director, Bureau of Legal Dentistry, University of

British Columbia, Canada

${ }^{*}$ Correspondence to: David Sweet, 146-2355 East

Mall, University of British Columbia, Vancouver, BC, Canada V6T $1 Z 4$

email:dsweet@interchange.ubc.ca

REFEREED PAPER

Received 22.12.99; Accepted 24.07.00

(C) British Dental Journal 2001; 190: 359-366 high degree of certainty) that the remains of a decedent and a person represented by antemortem (before death) dental records are the same individual. Information from the body or circumstances usually contains clues as to who has died. Secondly, in those cases where antemortem records are not available, and no clues to the possible identity exist, a postmortem (after death) dental profile is completed by the forensic dentist suggesting characteristics of the individual likely to narrow the search for the antemortem materials. $^{2}$

In brief

- Forensic dentistry plays a major role in body identification

- Several methods of dental identification exist

- DNA use in forensic dentistry

- Case examples of dental identifications

Dental identification of humans occurs for a number of different reasons (Table 1) and in a number of different situations. ${ }^{3}$ The bodies of victims of violent crimes, ${ }^{4,5}$ fires, ${ }^{6}$ motor vehicle accidents and work place accidents, ${ }^{7}$ can be disfigured to such an extent that identification by a family member is neither reliable nor desirable. ${ }^{8}$ Persons who have been deceased for some time prior to discovery and those found in water also present unpleasant and difficult visual identifications. Dental identifications have always played a key role in natural and manmade disaster situations and in particular the mass casualties normally associated with

\begin{tabular}{|c|l|}
\hline Table I & \begin{tabular}{|l} 
Common reasons for identification of found \\
human remains
\end{tabular} \\
\hline Criminal & $\begin{array}{l}\text { Typically an investigation to a criminal death cannot begin } \\
\text { until the victim has been positively identified }\end{array}$ \\
\hline Marriage & $\begin{array}{l}\text { Individuals from many religious backgrounds cannot remarry } \\
\text { unless their partners are confirmed deceased }\end{array}$ \\
\hline Monetary & $\begin{array}{l}\text { The payment of pensions, life assurance and other benefits } \\
\text { relies upon positive confirmation of death }\end{array}$ \\
\hline Burial & $\begin{array}{l}\text { Many religions require that a positive identification be made } \\
\text { prior to burial in geographical sites }\end{array}$ \\
\hline Social & $\begin{array}{l}\text { Society's duty to preserve human rights and dignity beyond } \\
\text { life begins with the basic premise of an identity }\end{array}$ \\
\hline Closure & $\begin{array}{l}\text { The identification of individuals missing for prolonged periods } \\
\text { can bring sorrowful relief to family members }\end{array}$ \\
\hline
\end{tabular}






Fig. I An example of postmortem dental charting aviation disasters. ${ }^{9-12}$ Because of the lack of a comprehensive fingerprint database, dental identification continues to be crucial in the United Kingdom.

\section{Comparative dental identification}

Many people are familiar with the concept of dental identification; it is frequently mentioned on television news. But the nuances and complexities of the process are rarely understood. The central dogma of dental identification is that postmortem dental remains can be compared with antemortem dental records, including written notes, study casts, radiographs, etc, to confirm identity. Clearly, individuals with numerous and complex dental treatments are often easier to identify than those individuals with little or no restorative treatment. The teeth not only represent a suitable repository for also survive most postmortem events that can disrupt or change other body tissues. ${ }^{2}$ such unique and identifying features, they
Typically, human remains are found and reported to the police who then initiate a request for dental identification. Often a presumptive or tentative identification is available (ie wallet or driving licence may be found on the body) and this will enable antemortem records to be located. In other instances, the geographical location in which the body is found or other physical characteristics and circumstantial evidence, may enable a putative identification to be made, frequently using data from the missing persons' database. Antemortem records are then obtained from the dentist of record.

The forensic dentist produces the postmortem record by careful charting and written descriptions of the dental structures and radiographs (Fig. 1). If the antemortem records are available at this time, postmortem radiographs should be taken to replicate the type and angle of these. ${ }^{13}$ Radiographs should be marked with a rubberdam punch to indicate antemortem and postmortem to prevent confusion - one hole for antemortem films and two holes for postmortem films.

Once the postmortem record is complete, a comparison between the two records can be carried out. A methodical and systematic comparison is required, examining each tooth and surrounding structures in turn. While dental restorations figure significantly in the identification process, many other oral features are assessed (Table 2), and these play an increasingly important role in those individuals with minimal restorations. Because of the progressive decrease in dental caries,

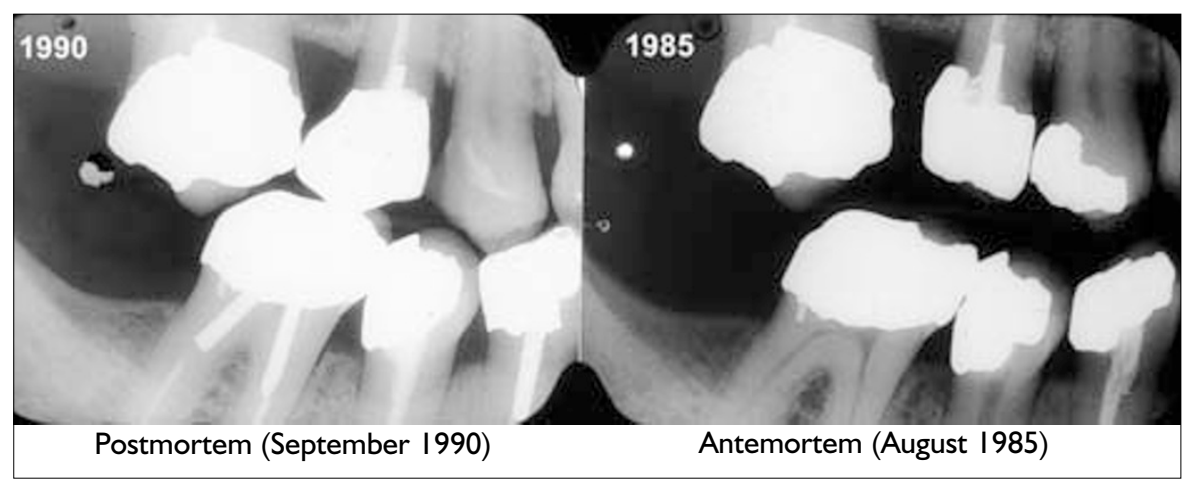

Fig. 2 An example of the comparison of postmortem and antemortem radiographs to determine identity. The pattern, shapes and sizes of individual dental treatments present in one record are compared with similar traits and characteristics in the other record. In this case it was determined that the records originated from the same person. This established a positive identification. Note that there are several discrepancies present, (eg endodontic treatment of teeth LR5 (45) and LR6(46) in the postmortem record) but these can be explained as a result of the time interval between the two records and the additional dental treatments performed during this period 


\section{Teeth}

\section{Teeth present}

a. Erupted

b. Unerupted

c. Impacted

Missing teeth

a. Congenitally

b. Lost antemortem

c. Lost postmortem

Tooth type

a. Permanent

b. Deciduous

c. Mixed

d. Retained primary

e. Supernumerary

Tooth position

a. Malposition

Crown morphology

a. Size and shape

b. Enamel thickness

c. Contact points

d. Racial variations

\section{Crown pathology}

a. Caries

b. Attrition, abrasion, erosion

c. Atypical variations, enamel pearls, peg laterals etc.

d. Dentigerous cyst

Root morphology

a. Size

b. Shape

c. Number

d. Divergence of roots

Root morphology

a. Dilaceration

b. Root fracture

c. Hypercementosis

d. Root resorption

e. Root hemisections
Pulp chamber/root canal morphology
a. size, shape and number
b. Secondary dentine

Pulp chamber/root canal pathology

a. Pulp stones, dystrophic calcification

c. Root canal therapy

d. Retrofills

e. Apicectomy

Periapical pathology

a. Abscess, granuloma or cysts

b. Cementomas

c. Condensing osteitis

Dental restorations

I. Metallic

a. Non-full coverage

b. Full coverage

2. Non-metallic

a. Non-full coverage

b. Laminates

c. Full coverage

3. Dental implants

4. Bridges

5. Partial and full removable prosthesis

\section{Periodontal tissues}

Gingival morphology and pathology

a. Contour, recession, focal/diffuse, enlargements, interproximal craters

b. Colour - inflammatory changes, physiological (racial) or pathological pigmentations

c. Plaque and calculus deposits

Periodontal ligament morphology and pathology
a. Thickness
b. Widening
c. Lateral periodontal cysts and similar

Alveolar process and lamina dura

a. Height, contour, density of crestal bone

b. Thickness of interradicular bone

c. Exostoses, tori

d. Pattern of lamina dura

e. Bone loss (horizontal/vertical)

f. Trabecular bone pattern and bone islands

g. Residual root fragments

\section{Anatomical features}

Maxillary sinus

a. Size, shape, cysts

b. Foreign bodies, fistula

c. Relationship to teeth

Anterior nasal spine

a. Incisive canal (size, shape, cyst)

b. Median palatal suture

Mandibular canal

a. Mental foramen

b. Diameter, anomalous

c. Relationship to adjacent structures

Coronoid and condylar processes

a. Size and shape

b. Pathology

Temperomandibular joint

a. Size, shape

b. Hypertrophy/atrophy

c. Ankylosis, fracture

d. Arthritic changes

Other pathologies
a. Developmental cysts
b. Salivary gland pathology
c. Reactive/neoplastic
d. Metabolic bone disease
e. Focal or diffuse radiopacities
f. Evidence of surgery
g. Trauma - wires, surgical pins etc. 


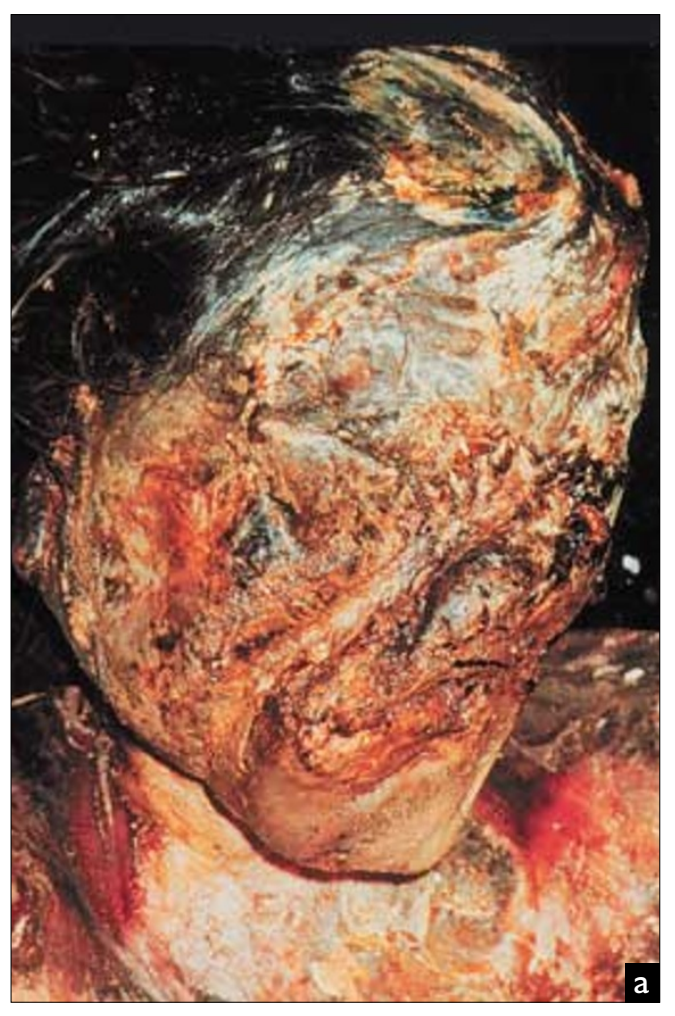

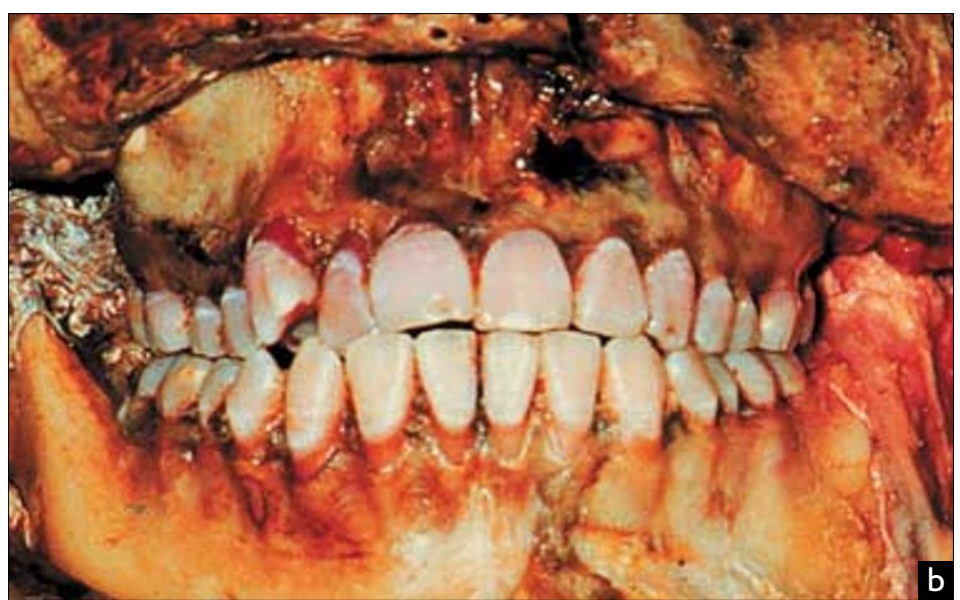

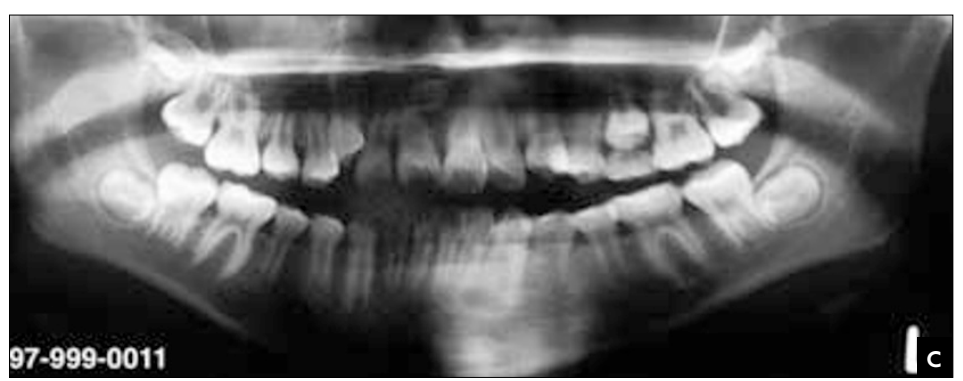

Antemortem panoramic radiograph
Fig. 3 Example of a comparative dental identification case. The body depicted in the images is that of a sixteen-year-old female. She was found encased in a waterbed frame after being reported missing for over a year. A victim of homicide, she became mummified in the dry, cool conditions under the bed. The bed, used frequently, was removed when a lodger left the apartment and the body was discovered. Despite the condition of the soft tissues the teeth remain in perfect condition. The antemortem and postmortem radiographs are shown below. A positive identification, this case illustrates a nonrestorative case. Note the mesiodens

so-called non-restorative cases are likely to become more common. ${ }^{14}$

Similarities and discrepancies should be noted during the comparison process. ${ }^{15}$ There are two types of discrepancy, those that can be explained and those that cannot. Explainable discrepancies normally relate to the time elapsed between the antemortem and postmortem records. Examples include teeth extracted or restorations placed or enlarged (ie MO amalgam that is now MOD). Figure 2 illustrates explainable discrepancies. If a discrepancy is unexplainable, for example a tooth is not present on the antemortem record but is present on the postmortem record then an exclusion must be made.

A range of conclusions can be reached when reporting a dental identification. The American Board of Forensic Odontology recommends that these be limited to the following four conclusions: ${ }^{16}$



Postmortem full-mouth radiographic survey

- Positive identification: The antemortem and postmortem data match in sufficient detail, with no unexplainable discrepancies, to establish that they are from the same individual.

- Possible identification: the antemortem and postmortem data have consistent features but, because of the quality of either the postmortem remains or the antemortem evidence, it is not possible to establish identity positively.

- Insufficient evidence: The available information is insufficient to form the basis for a conclusion.

- Exclusion: the antemortem and postmortem data are clearly inconsistent.

It is important to note that there is no minimum number of concordant points or features that are required for a positive identification. In many cases a single tooth can be used for identification if it contains sufficient unique features. Equally, a full-mouth series of radiographs may not reveal suffi- cient detail to render a positive conclusion. ${ }^{16}$ The discretion of identification lies with the odontologist who must be prepared to justify the conclusions in court, surely the ultimate in peer-review. Figure 3 illustrates a case of dental identification.

\section{Postmortem dental profiling}

When antemortem dental records are unavailable and other methods of identification are not possible, the forensic dentist can assist in limiting the population pool to which the deceased is likely to belong and thus increase the likelihood of locating antemortem dental records. ${ }^{2}$ This process is known as postmortem dental profiling. The information from this process will enable a more focused search for antemortem records. A postmortem dental profile will typically provide information on the deceased's age, ancestry background, sex and socio-economic status. In some instances it is possible to provide additional 


\section{PRACTICE forensic dentistry}

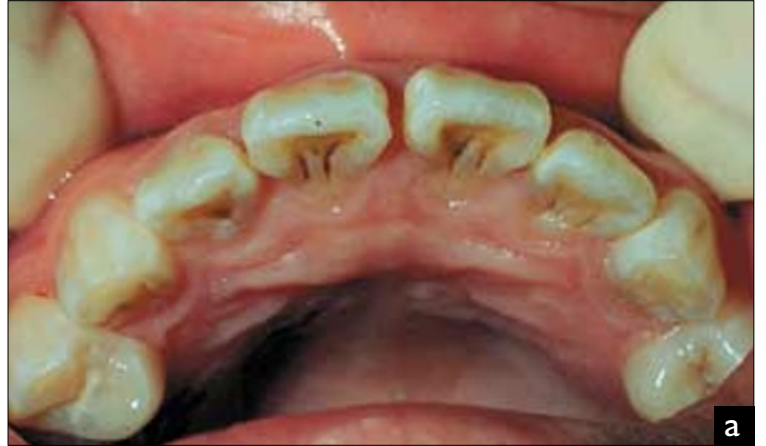

Fig. 4 (a) Shovel-shaped incisors and (b) the Cusp of Carabelli are both dental indicators for ethnicity



information regarding occupation, dietary habits, habitual behaviours and occasionally on dental or systemic diseases.

Forensic anthropologists most often provide details of osteological studies, but forensic dentists can assist in the process. ${ }^{17-22}$ The determination of sex and ancestry can be assessed from skull shape and form. Generally, from skull appearance, forensic dentists can determine race within the three major groups: Caucasoid, Mongoloid and Negroid. Additional characteristics, such as cusps of Carabelli, shovel-shaped incisors and multi-cusped premolars, can also assist in determination of ancestry (Fig. 4). ${ }^{23} \mathrm{Sex}$ determination is usually based on cranial appearance, as no sex differences are apparent in the morphology of teeth. Microscopic examination of teeth can confirm sex by the presence or absence of Y-chromatin and DNA analysis can also reveal sex. ${ }^{24,25}$

Dental structures can provide useful indictors to the individual's chronological age. ${ }^{22}$ The age of children (including foetuses and neonates) can be determined by the analysis of tooth development and subsequent comparison with developmental charts. Conclusions are usually accurate to approximately \pm 1.5 years. Charts such as those developed by Ubelaker graphically illustrate the development of the dentition from 5 months in utero to 35 years, illustrating the deciduous, mixed and permanent dentitions. ${ }^{2}$ It is important to note that when determining sub-adult ages, eruption dates of the teeth are highly variable and the actual developmental stages of the teeth are more accurate. Third molar development is used by some forensic dentists to assign age to young adults although doubts concerning the accuracy of this technique will be raised by the practitioner's own experience of the variability of these teeth. ${ }^{26}$ Those who
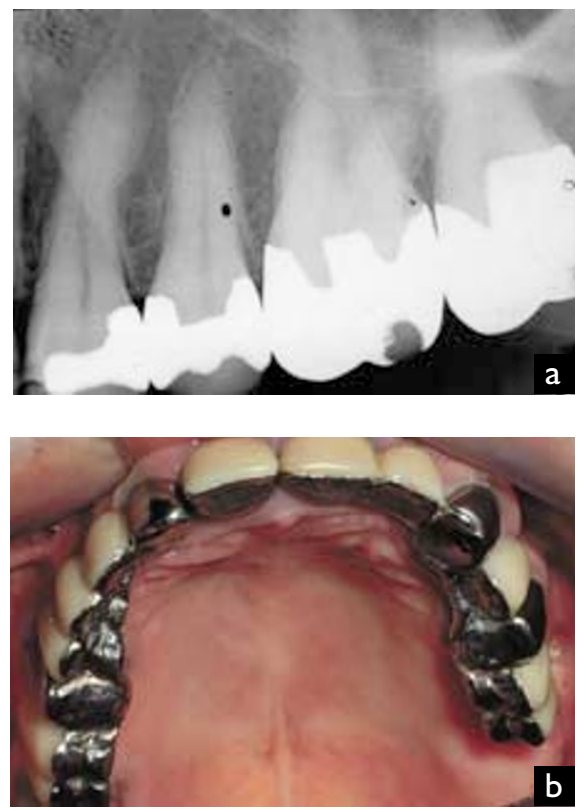

Fig. 5 The quality and type of dental treatment may indicate an individual's country of residence: a) Dental treatment of high quality, which is consistent with North American and European standards.

b) Unusual dental treatments involving the use of permanent acrylic and stainless steel crowns. This treatment was performed in Russia advocate third molar use claim an accuracy of \pm 4 years. ${ }^{27}$ Middle-aged and older adults present difficulties. Periodontal disease progression, excessive wear, multiple restorations, extractions, bone pathosis and complex restorative work may indicate an older individual. Accuracy using these highly-variable markers is in the range of $\pm 10-12$ years. Some odontologists advocate the use of aspartic acid racemization, claiming an accuracy of \pm 4 years. ${ }^{28}$ Additional methods include the use of SEM-EDXA, a method used to examine dentine in relation to age determination. A recent study from the UK examined the use of root length in the determination of age in paediatric cases. ${ }^{29}$

The presence of erosion can suggest alcohol or substance abuse, an eating disorder or even hiatus hernia while stains can indicate smoking, tetracycline use or betel nut chewing. ${ }^{30-39}$ Unusual wear patterns may result from pipe stems, cigarette holders, hairpins, carpet tacks or previous orthodontic treatment. ${ }^{2,40}$ The quality, quantity and presence or absence of dental treatment may give an indication of socio-economic status or likely country of residence (Fig. 5). ${ }^{41}$ Figure 6 shows an example of postmortem dental profiling.

If the postmortem profile does not elicit the tentative identity of the deceased it may be necessary to reconstruct the individual's appearance during life. This is the responsibility of forensic artists who use the dental profile to help with the facial reproduction.

\section{Other methods of dental identification}

The two processes described above, comparative identification and postmortem profiling, represent the most common methods of dental identification. However, in some instances more novel and innovative techniques have been applied. There have been a number of requests from individuals and dental organizations over the years to insist that dental prostheses are labelled with the patient's name or a unique number. ${ }^{42}$ The NHS provide a fee for dentists who label their patients dentures, although this is often only used in instances where the wearer is a resident in a care home 
or other establishment with a central sterilizing system for dental prostheses. Labelled dentures can be of great assistance in the identification of individuals. ${ }^{43}$

Unlabelled dentures have been recovered from patients and then fitted to casts retained by the treating dentist or laboratory, and this has been an accepted method of identification. ${ }^{44}$ Other dental appliances, such as removable orthodontic braces have also been used for identification purposes. Whittaker describes a case where a removable orthodontic appliance was used to identify a victim of a house fire. ${ }^{45}$ Authors have also described the use of palatal rugae patterns rendered on dental casts to compare with found remains. Positive identifications have resulted from this technique. ${ }^{46}$

Dental materials have provided clues to assist identification. One of the authors (DS) has used SEM-EDX to identify the composition of a glass-ionomer restoration and then traced this back to a prison where the filling was placed. Dental records secured the identification of the individual. In another case, it was possible to identify Kevlar fibers that had been placed within a lower denture to reinforce it. This rare procedure enabled an identification of the wearer who was a victim of homicide.

\section{Role of DNA in dental identifications}

Because of the resistant nature of dental tissues to environmental assaults, such as incineration, immersion, trauma, mutilation and decomposition, teeth represent an excellent source of DNA material. ${ }^{47}$ When conventional dental identification methods fail, this biological material can provide the necessary link to prove identity. ${ }^{48}$ With the advent of the polymerase chain reaction (PCR), a technique that allows amplification of DNA at pre-selected, specific sites, this source of evidence is becoming increasingly popular with investigators. Comparison of DNA preserved in and extracted from the teeth of an unidentified individual can be made to a known antemortem sample (stored blood, hairbrush, clothing, cervical smear, biopsy, etc) or to a parent or sibling. ${ }^{2}$

\section{Genomic DNA}

Genomic DNA is found in the nucleus of each cell and represents the DNA source for most forensic applications, (there are no nuclei, and hence there is no DNA, in red blood cells.) When body tissues have decomposed, the structures of the enamel, dentine and pulp complex persist. It is necessary to extract the DNA from the calcified tissues. In the authors' laboratory, the cryogenic grinding method is employed (Fig. 7). ${ }^{48}$ Teeth represent an excellent source of genomic DNA. Indeed, the
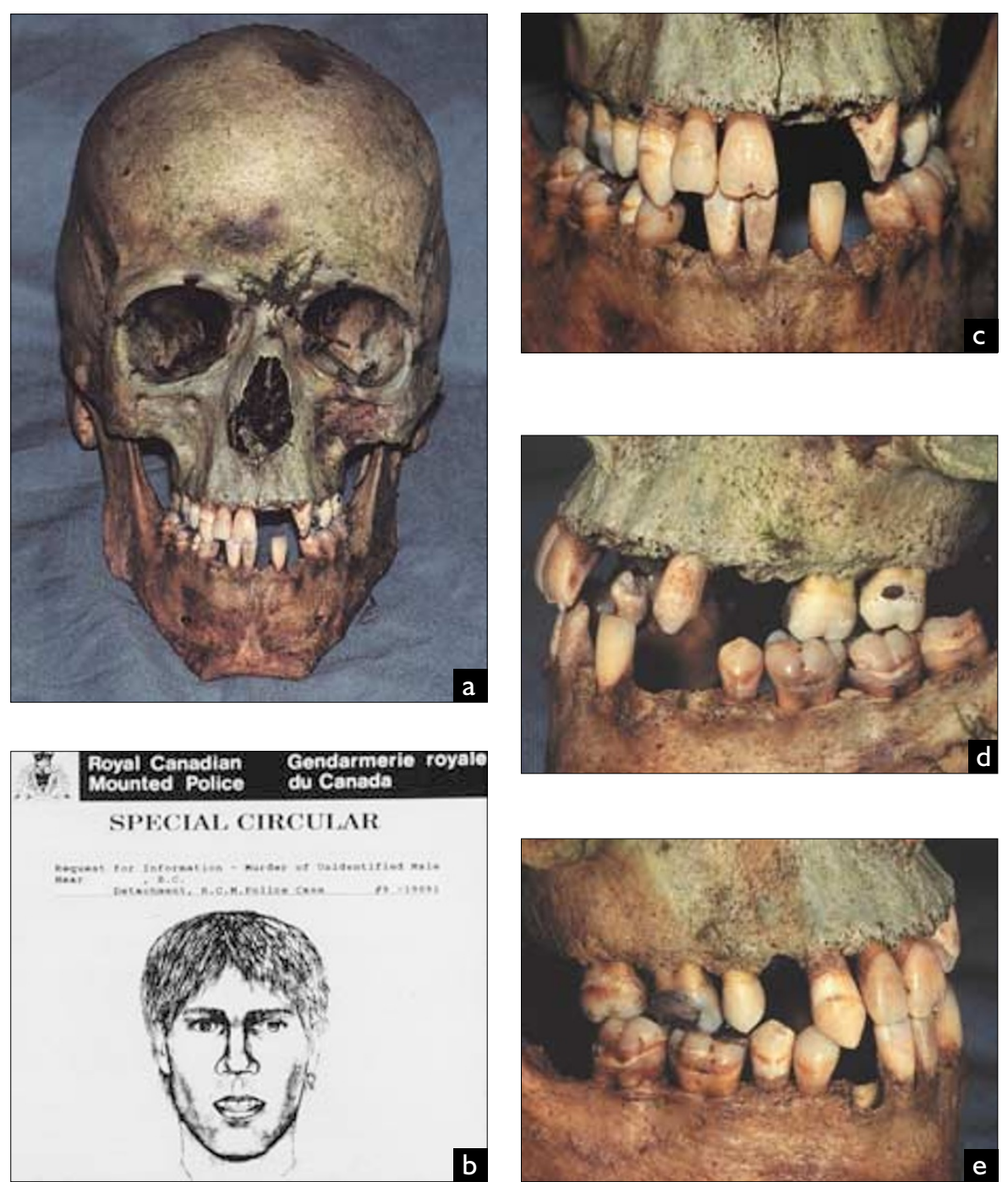

Fig. 6 A postmortem profiling identification case. Investigators were unable to establish a tentative identification and requested a postmortem dental profile. The skeletal pattern and dental characteristics suggested the following profile: Caucasian, male, aged 25-35 years at death, moderate adult periodontitis, nicotine stains, lack of recent dental treatment and previous treatment to Canadian standards. Using this information, a forensic artist produced a facial reproduction. Subsequently, the body was identified as that of a 28 -year-old missing white male smoker

authors have found that even root-filled teeth supply sufficient biological material for PCR analysis! ${ }^{48}$

PCR-based analysis produces a DNA profile that can be compared with known anteillustrates a case using determine the identity of found remains. The identification of individuals is not the only use for dental DNA. The technique has

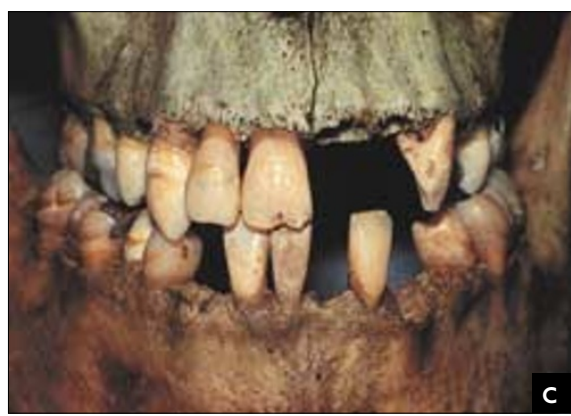
. 


\section{PRACTICE $\underline{\text { forensic dentistry }}$}


Fig.7 Cryogenic grinding is used to extract DNA from calcified tissues such as teeth. In a freezer mill a ferromagnetic plunger is oscillated back-and-forth in alternating electric current. Liquid nitrogen is used to cool the sample, which results in making it extremely brittle and also protects DNA from heat degradation. The tooth is reduced to a powder to increase surface area and expose trapped cells to biochemical agents that release DNA into solution

allowed criminal investigators to link victims to crime scenes once the body has been removed and incinerated. ${ }^{49}$

\section{Mitochondrial DNA}

In addition to genomic DNA, cells contain mitochondrial DNA (mtDNA), the sequence of building blocks of which can be determined to assist in identification. The main advantage of mtDNA is that there is a high copy number in each cell caused by the high number of mitochondria present in most cells. This infers that in cases where genomic DNA cannot be analyzed, possibly because it is too degraded, mtDNA may be present in sufficient quantity. In addition to its higher copy number, mtDNA is maternally inherited. ${ }^{50}$ This maternal inheritance pattern confers the same mtDNA sequence, barring mutations, upon siblings and all their maternal relatives. This has important implications for the identification of individuals for which there is no antemortem comparison sample. Although mitochondrial DNA is still in its infancy in forensic casework, it is a powerful technique that is likely to become commonplace in the future.

\section{Dental identification in mass \\ disasters}

The identification of large numbers of casualties in mass disasters are complex and fraught with hazards, both physically and emotionally. ${ }^{51,52}$ The identification process is fundamentally the same as that in a rou-

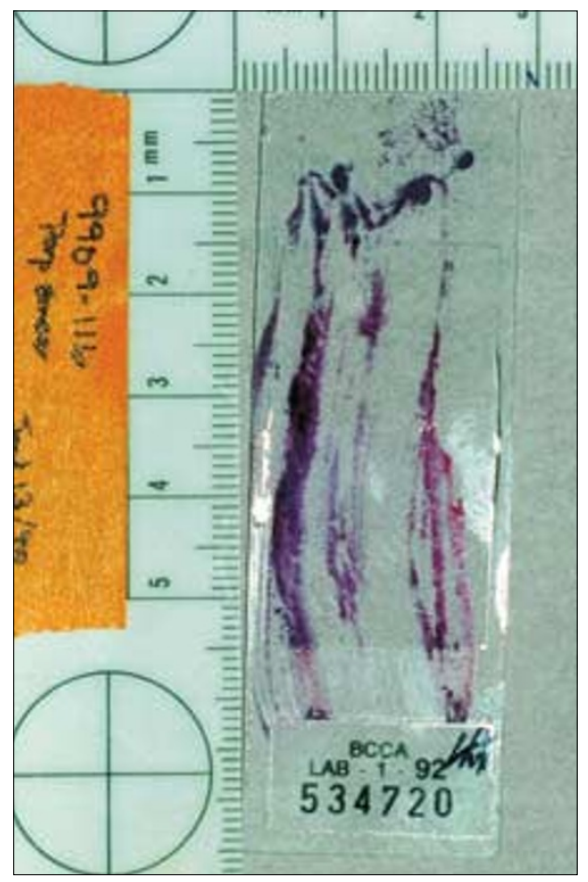

Pap smear (1992)

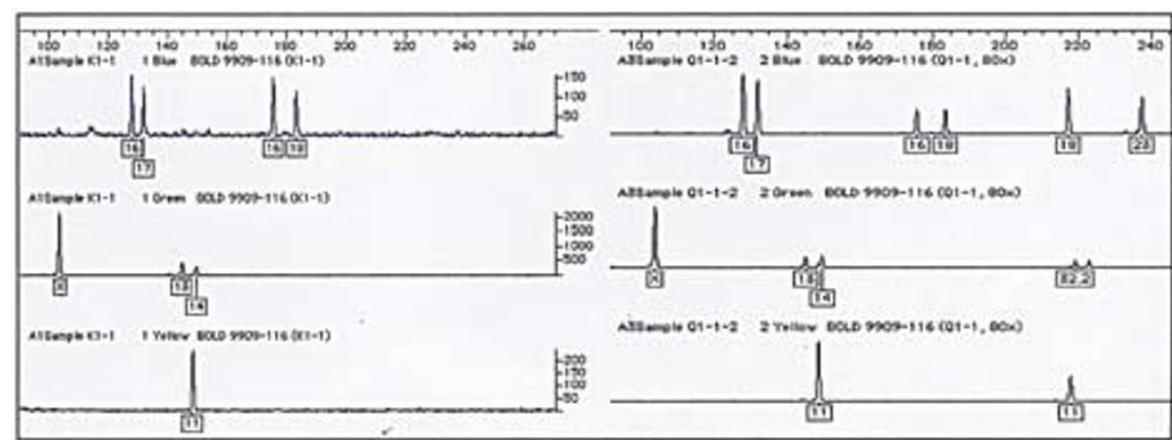

DNA profile from Pap smear tine comparative dental identification, but the inherent problems are magnified. ${ }^{53}$ Problems of body fragmentation, mutilation, commingling and incineration, idiosyncratic dental records from numerous regions, poor working conditions and psychological stresses all confound the identification process. The key to successful mass disaster identification is preparedness. ${ }^{54}$ Many jurisdictions have dental identification teams and disaster plans in place. Mock disaster scenarios that help dentists prepare for the disaster situation have proven to be successful. ${ }^{54,55}$

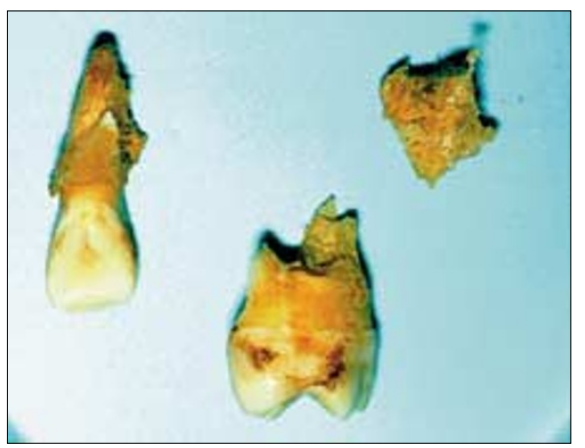

Teeth recovered from body (1999)

Fig. 8 The use of DNA from teeth to prove identity. Circumstantial evidence established the probable identity of a found human skull. Antemortem dental records were not available for comparison.

Medical records revealed the availability of a Pap (cervical) smear. Partial degradation of DNA from teeth produced a profile at eight genetic loci. These were compared with the DNA profile obtained from the Pap smear and established that the samples originated from the same source 


\section{Conclusions}

Forensic dentistry plays a major role in the identification of those individuals who cannot be identified visually or by other means. The unique nature of our dental anatomy and the placement of custom restorations ensure accuracy when the techniques are correctly employed. In this brief overview, the authors have shown the reader some of the traditional and upcoming techniques in this fascinating field.

The authors gratefully acknowledge the suggestions of Dr David Kennedy of Vancouver, Canada with respect to the submission of this article to the British Dental Journal. Mr. Pretty is supported by a grant from the Forensic Science Society (UK).

1. Jones D G. Odontology often is final piece to grim puzzle. J Calif Dent Assoc 1998; 26: 650 651.

2. Sweet D, DiZinno J A. Personal identification through dental evidence-tooth fragments to DNA. J Calif Dent Assoc 1996; 24: 35-42.

3. Weedn V W. Postmortem identifications of remains. Clin Lab Med 1998; 18: 115-137.

4. Whittaker D K, Richards B H, Jones M L. Orthodontic reconstruction in a victim of murder. Br J Orthod 1998; 25: 11-14.

5. Rothwell B R, Haglund W, Morton T H. Dental identification in serial homicides: the Green River Murders. J Am Dent Assoc 1989; 119: 373-379.

6. Andersen L, Juhl M, Solheim T, Borrman H. Odontological identification of fire victimspotentialities and limitations. Int J Legal Med 1995; 107: 229-234.

7. Dorion R B. Disasters big and small. J Can Dent Assoc 1990; 56: 593-598.

8. Malkowski F S. Forensic dentistry, a study of personal identification. Dent Stud 1972; 51: 42-44.

9. Brannon R B, Kessler H P. Problems in mass disaster dental identification: a retrospective review. J Forensic Sci 1999; 44: 123-127.

10. Alexander C J, Foote G A. Radiology in forensic identification: the Mt. Erebus disaster. Australas Radiol 1998; 42: 321-326.

11. Chapenoire S, Schuliar Y, Corvisier J M. Rapid, efficient dental identification of $92 \%$ of 13 train passengers carbonized during a collision with a petrol tanker. Am J Forensic Med Pathol 1998; 19: 352-355.

12. Clark D H. An analysis of the value of forensic odontology in ten mass disasters. Int Dent J 1994; 44: 241-250.

13. Goldstein M, Sweet D J, Wood R E. A specimen positioning device for dental radiographic identification. Image geometry considerations. J Forensic Sci 1998; 43: 185-189.

14. Murray J. Prevention of oral disease. Oxford: Oxford University Press, 1986.

15. Silverstein H. Comparison of antemortem and postmortem findings. In: Bowers C M Bell G, (eds). Manual of forensic odontology. 3rd ed. Ontario: Manticore, 1995.

16. American Board of Forensic Odontology. Body identification guidelines. J Am Dent Assoc 1994 125: 1244-1254

17. Steyn M, Iscan M Y. Sexual dimorphism in the crania and mandibles of South African whites. Forensic Sci Int 1998; 98: 9-16.

18. Burris B G, Harris E F. Identification of race and sex from palate dimensions. J Forensic Sci 1998; 43: 959-963.

19. Hsu J W, Tsai P L, Hsiao T H et al. The effect of shovel trait on Carabelli's trait in Taiwan Chinese and Aboriginal populations. J Forensic Sci 1997; 42: 802-806.

20. Solheim T. A new method for dental age estimation in adults. Forensic Sci Int 1993; 59: 137-147.

21. Shapiro H L. Forensic anthropology. Ann NY Acad Sci 1978; 318: 3-9.

22. Noble H W. The estimation of age from the dentition. J Forensic Sci Soc 1974; 14: 215-221.

23. Whittaker D K, Rawle L W. The effect of conditions of putrefaction on species determination in human and animal teeth. Forensic Sci Int 1987; 35: 209-212.

24. Adachi H. Studies on sex determination using human dental pulp. II. Sex determination of teeth left in a room. Nippon Hoigaku Zasshi 1989; 43: 27-39.

25. Sweet D, Hildebrand D, Phillips D. Identification of a skeleton using DNA from teeth and a PAP smear. J Forensic Sci 1999; 44: 630-633.

26. Mincer H H, Harris F, Berryman H E. The ABFO study of third-molar development and its use as an estimator of chronological age. $J$ Forensic Sci 1993; 38: 379-390

27. Hongwei S, Jingtao J, Cameron J M. Age determination of the molars. Med Sci Law 1991; 31: 65-68.

28. Ogino T, Ogino H, Nagy B. Application of aspartic acid racemization to forensic odontology: post mortem designation of age at death. Forensic Sci Int 1985; 29: 259-267.

29. Liversidge H M, Molleson T I. Developing permanent tooth length as an estimate of age. $J$ Forensic Sci 1999; 44: 917-920.

30. Harley K. Tooth wear in the child and the youth. Br Dent J 1999; 186: 492-496.

31. Murray M O, Wilson N H. Ecstasy related tooth wear. Br Dent J 1998; 185: 264.

32. Bartlett D. Regurgitated acid as an explanation for tooth wear [letter, comment]. Br Dent J 1998; 185: 210

33. Nunn J, Shaw L, Smith A. Tooth wear-dental erosion. Br Dent J 1996; 180: 349-352.

34. Robb N D, Smith B G. Prevalence of pathological tooth wear in patients with chronic alcoholism. Br Dent J 1990; 169 367-369.

35. Milosevic A, Slade P D. The orodental status of anorexics and bulimics. Br Dent J 1989; 167: 66-70.

36. Smith B G, Knight J K. A comparison of patterns of tooth wear with aetiological factors. Br Dent J 1984; 157: 16-19.

37. Lochary M E, Lockhart P B, Williams W T. Doxycycline and staining of permanent teeth. Pediatr Infect Dis J 1998; 17: 429-431.

38. Livingston H M, Dellinger T M. Intrinsic staining of teeth secondary to tetracycline. Ann Pharmacother 1998; 32: 607.

39. Cuff M J, McQuade M J, Scheidt M J, Sutherland D E, Van Dyke T E. The presence of nicotine on root surfaces of periodontally diseased teeth in smokers. J Periodontol 1989; 60: 564-569.

40. Gupta B N. Occupational diseases of teeth. J Soc Occup Med 1990; 40: 149-152.

41. Maupome G, MacEntee M I. Prosthodontic profiles relating to economic status, social network, and social support in an elderly population living independently in Canada. J Prosthet Dent 1998; 80: 598-604.

42. Borrman H I, DiZinno J A, Wasen J, Rene N. On denture marking. J Forensic Odontostomatol 1999; 17: 20-26

43. Marella G L, Rossi P. An approach to identification by means of dental prostheses in a burnt corpse. J Forensic Odontostomatol 1999; 17: 16-19.

44. Jacob R F, Shalla C L. Postmortem identification of the edentulous deceased: denture tissue surface anatomy. J Forensic Sci 1987; 32: 698-702

45. Whittaker D K. A Colour Atlas of Forensic Dentistry. Saint-Louis: Harcourt, 1989

46. Thomas C J, van Wyk C W. The palatal rugae in identification. J Forensic Odontostomatol 1988; 6: 21-27.

47. Schwartz T R, Schwartz E A, Mieszerski L McNally L, Kobilinsky L. Characterization of deoxyribonucleic acid (DNA) obtained from teeth subjected to various environmental conditions. J Forensic Sci 1991; 36: 979-990.

48. Sweet D, Hildebrand D. Recovery of DNA from human teeth by cryogenic grinding. J Forensic Sci 1998; 43: 1199-1202.

49. Sweet D J, Sweet C H. DNA analysis of dental pulp to link incinerated remains of homicide victim to crime scene. J Forensic Sci 1995; 40: 310-314.

50. Hutchison C A, Newbold J E, Potter S S, Edgell $\mathrm{M} \mathrm{H}$. Maternal inheritance of mammalian mitochondrial DNA. Nature 1980; 251: 536-538

51. Morlang W M. Dentistry's vital role in disaster preparedness. J Calif Dent Assoc 1996; 24: 63-66.

52. Clark D H. The British experience in mass disaster dental identification. United Kingdom disasters. A historical review. Acta Med Leg Soc 1990; 40: 159-165.

53. Morlang W M. Mass disaster management update. CDAJ 1986; 14: 49-57.

54. Pretty I A, Webb D A, Sweet D. The design and assessment of mock mass disasters for dental personnel. J Forensic Sci 2001; 46: 74-79.

55. Woodward J D. Identification of victims following a mass disaster. Ky Dent J 1982; 34 $37-41$. 